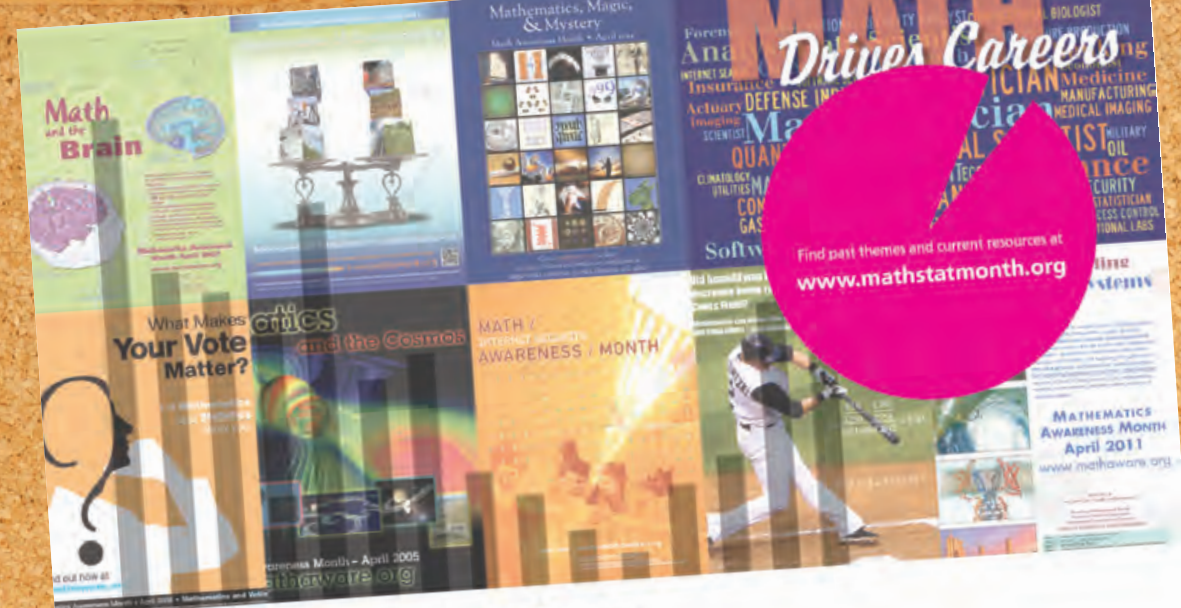

\title{
Mathematics and Statistics Awareness Month
} April marks a time to increase the Why? Both subjects play a significant of mathematics and statistics. Why real-world problems-internet security, role in addressing many rimate change, the data deluge, and much more. sustainability, disease, climate change, the data revealing new results and Research in these and other areas is medicine, manufacturing, energy, applications every day in fields such as medicine, manufact important biotechnology, and business. Mathematics and statistics are impow systems drivers of innovation in our technological world, in which and methodologies continue to become more complex. Organize and host activities in April for Mathematics and Statistics competitions, Organize and honth! Past activities have included workshops, compibits. festivals, lectures, symposia, department open houses, math art festivals, lectures, sympadings. Share your activities on social media.

\section{MathStatMonth @MathAware}

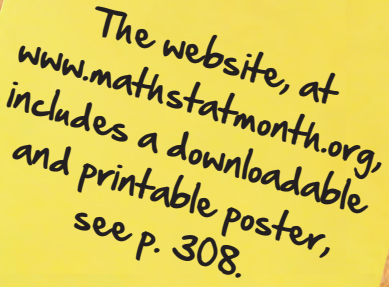

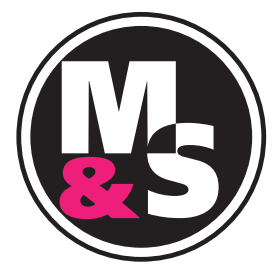

Starting this April, "Mathematics Awareness Month" has become "Mathematics and Statistics Awareness Month."

Further, the Joint Policy Board for Mathematics - consisting of the American Mathematical Society, the American Statistical Association, the Mathematical Association of America, and the Society for Industrial and Applied Mathematics - has decided that to simplify coordination efforts there will no longer be an annual theme.

In this issue of Notices we feature four pieces on Mathematics and Statistics Awareness Month: Michael Barany traces the origins of mathematics awareness to World War II; Andreas Daniel Matt describes the IMAGINARY international math exhibitions; David Eisenbud and Ronald Wasserstein provide short opinion pieces on the celebration of mathematics and statistics. 


\section{The World War II Origins of Mathematics Awareness}

Michael J. Barany

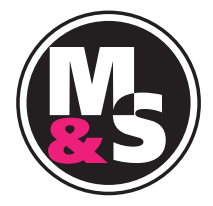

Since ancient times, advocates for mathematics have argued that their subject is foundational for many areas of human endeavor, though the areas and arguments have changed over the years. Much newer, however, is the idea that mathematicians should systematically try to promote the usefulness or importance of mathematics to the public. This effort, which I shall generically call "mathematics awareness," was largely an American inven-

\section{To understand} the origins of mathematics awareness, one must follow the money. tion. One outward manifestation was the 1986 inauguration, by President Ronald Reagan, of the first Mathematics Awareness Week. Every year since then, mathematicians and mathematics educators in the United States have dedicated a weekor, beginning in 1999, the month of April-to raising public awareness of "the importance of this basic branch of science to our daily lives," as Reagan put it.

While today's mathematics awareness is focused on schools and on peaceful applications of mathematics, a direct line connects it to its origins in a very different kind of activity: mathematicians promoting their expertise to leaders of the American war effort during World War II. Recent mathematics awareness has focused on encouraging

Michael J. Barany is a postdoctoral fellow in the Dartmouth College Society of Fellows. His e-mail address is michae1@mbarany.com, and his website is mbarany. com.

For permission to reprint this article, please contact:

reprint-permission@ams.org.

DOI: http://dx.doi.org/10.1090/noti1506

\section{A War of Mathematics}

World War II was not the first war that mathematicians attempted to characterize as "a war of mathematics," but it was the first one where the characterization appeared to stick. In addition to lobbying elite policymakers, mathematicians wrote articles for the popular press and offered radio broadcasts that attempted to explain why mathematics mattered in terms the masses could understand. For example, Bennington P. Gill, who served as AMS treasurer from 1938 to 1948, gave an interview in 1942 with WNYC for their series on The Role of Science in War, see Www. wnyc. org/story/ bennington-p-gi11/.

more people to take up the discipline. However, wartime and early postwar mathematics awareness centered on securing resources for those already in the profession. To understand the origins of mathematics awareness, one must follow the money.

\section{A Discipline in Need}

For most of the discipline's history, mathematicians have supported their research either through independent wealth or through patronage from the wealthy. Universities and a select few other academic institutions-all, themselves, historically channels for wealthy patronage-eventually became the dominant sites and funders of mathematical scholarship. So long as publication and travel were relatively small parts of such scholarship, this arrangement suited mathematicians' needs well enough. But by the early twentieth century mathematicians were publishing and traveling much more than before and across greater distances. They needed new organizations and new sponsors to support their work.

Such were the rationales for mathematicians' first professional societies, many of which date to the latter part of the nineteenth century and the start of the twentieth. 


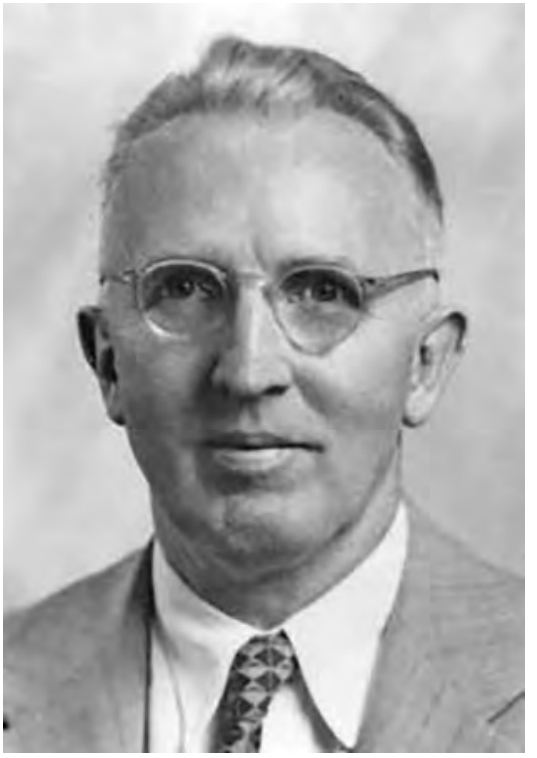

IAS mathematician Marston Morse, who served as AMS president during 1941-1942, approached the Rockefeller Foundation with the argument that his discipline was "unique... as having no natural sources of support."

porate sponsorship for their work, for instance from the American Telephone \& Telegraph Company, and considerably greater success courting major philanthropies such as the Rockefeller Foundation and Carnegie Corporation of New York. Yet these relationships tended to be piecemeal and tenuous. American mathematicians had successfully bid to host the 1924 International Congress of Mathematicians but ended up ceding the congress to Toronto after finding themselves unable to secure the needed financial backing. (John Charles Fields, on the other hand, managed to find enough money for the Toronto meeting that it concluded with a modest surplus, which provided the seed money for what became the Fields Medals.)

The Americans tried again to host an International Congress in 1940. When preliminary fundraising efforts again fell short, Institute for Advanced Study mathematician Marston Morse approached the Rockefeller Foundation with the argument that his discipline was "unique... as having no natural sources of support." Indeed, when it came to major donors, Rockefeller and Carnegie were the only relatively sure bets, and no grant was assured. To grow, American mathematics would need new constituencies and new sources of funding.

\section{Preparing for War}

The AMS suspended plans for the envisioned 1940 International Congress of Mathematicians following the German invasion of Poland in 1939. As war threatened to engulf Europe and beyond, American mathematicians thought back to their experiences of the Great War. Some concluded that a lack of coordination among American mathematicians had restricted their contributions to the previous war effort. Without such coordination, military leaders would have a hard time learning where mathematicians were needed and where the needed mathematicians could be found.

A new joint AMS-MAA War Preparedness Committee aimed to provide this coordination by synthesizing the lessons from the last war and positioning mathematicians for a new conflict that seemed sure to draw American involvement sooner or later. Marston Morse was appointed chair, and a subcommittee chaired by Dunham Jackson focused on mathematical research. The subcommittee included Marshall Stone, whose two-year presidency of the AMS would fall in the middle of the United States' official engagement in World War II. From start to finish, Stone advocated formal mathematical coordination with particular force and frequency. In a summer 1940 missive on "the organizational aspects of the research problems of national defense," Stone articulated three purposes for the subcommittee. First and most urgent was to find an efficient means to join together current "technical problems and competent mathematicians" who could solve them. Second, the US would need to make much greater use of mathematical techniques than it currently did. The third, long-range, goal was to make war service pay off for the US mathematical profession even after the war's end.

"If mathematics is to be brought to bear upon our defense problems in full measure," Stone then asserted, "we shall have to organize and conduct propaganda to this end." He anticipated an uphill struggle. The subcommittee would have to confront "not only the appalling limitations of our military officers, but also the general American attitude of antagonism to theory in general and to mathematical refinements in particular and the abysmal ignorance of the majority of intelligent Americans concerning the uses of mathematics."

\section{Enter Mina Rees}

The US military officially entered the war as 1941 drew to a close. The next year the AMS and MAA responded by dissolving the War Preparedness Committee and appointing a new War Policy Committee, with Marshall Stone (soon to be AMS president) as chair and Marston Morse (who was just finishing his own term as AMS president) in a supporting role. Soon, leaders from academia, philanthropy, and the military drew on approaches from their respective fields to develop for the US government a system for identifying problems and contracting them out to academic research groups. This formed the basis for a massive system of contracts that would support advanced mathematical research and training after the war, as well as the postwar system of government grants familiar to many mathema- 
ticians today. But mathematics awareness remained the exclusive province of a narrow elite.

Richard Courant, one of the academic leaders who helped to craft that system, used his wartime government connections both during and after the war to build his institute at New York University into one of the world's leading centers of mathematics. Perhaps even more important for postwar mathematics in and beyond the United States, however, was Courant's close associate Mina Rees. Although she had earned a PhD under Leonard Dickson from the University of Chicago, Rees's prospects within the mathematics profession were limited by widespread institutional sexism. At Courant's urging, Rees was appointed

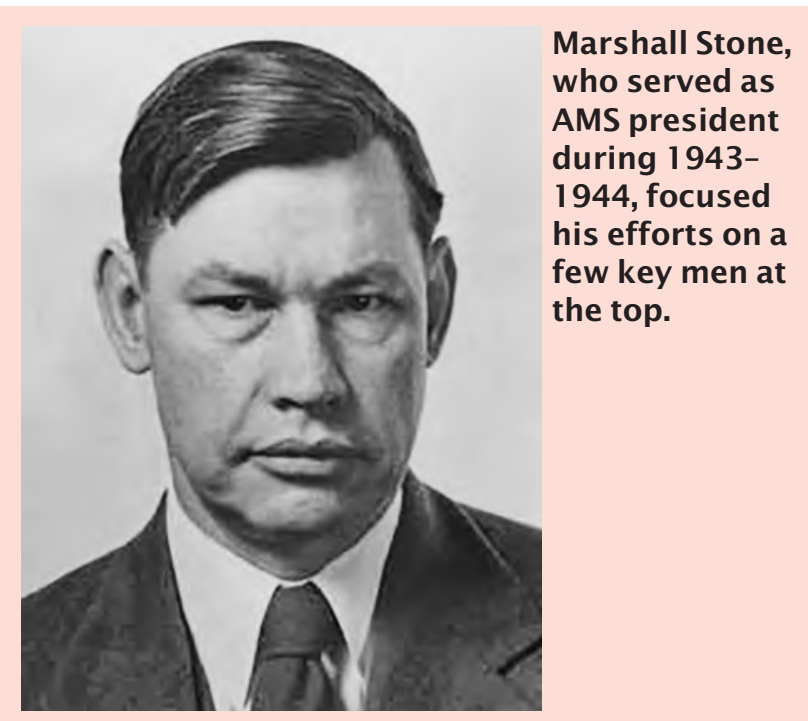

A Few Key Men at the Top

Marshall Stone's dim view of the public appreciation for mathematics led him to focus on a few "key men at the top" rather than aim to convince the masses or even the much smaller mass of officers and policymakers. Among those key men were Harvard president James Bryant Conant, chair of the National Defense Research Committee, and Frank Jewett, chairman of the Board of Directors of Bell Laboratories and president of the National Academy of Sciences. Referring to the commonplace characterization of the Great War as the chemist's war, Conant famously quipped on the front page of Chemical \& Engineering News in November 1941,"This is a physicist's war rather than a chemist's." According to AMS secretary Roland Richardson, when Conant shared the view with Jewett the latter shot back that "It may be a war of physics, but the physicists say it is a war of mathematics." At least one key man got the message.

Further Reading: Michael J. Barany, "Remunerative combinatorics: Mathematicians and their sponsors in the mid-twentieth century," in Mathematical Cultures: The London Meetings 2012-2014, edited by Brendan Larvor (Basel: Birkhäuser, 2016), pp. 329-346; preprint online at mbarany.com/publications.htm7. as technical aide to the main government clearinghouse for coordinating mathematicians' war service. There, she facilitated the broad array of contracts by gathering information, assessing outcomes, and making needed connections.

Stone, in 1944, expressed his frustration that the government "would display considerable reluctance to call on the leaders of our profession." In his view, mathematicians could and should have done much more to dedicate themselves wholly to the war effort. He himself set out immediately after the conclusion of his term as AMS president on a mission classified top secret to advise and assess Allied signal intelligence in India, Burma, and China in the first part of 1945.

Mathematicians in the US concluded the war with a range of views of their relative success or failure. While they did not lay claim to a breakthrough on the scale of the Manhattan Project as physicists would, mathematicians contributed to a great many of the United States' decisive wartime innovations in weaponry, aeronautics, provisioning, communications and intelligence, and other areas.

\section{Coordination for a Growing Discipline}

In 1946 Rees took over the mathematics arm of the Office of Naval Research (ONR), helping the navy to become a leading funder of research and publication in both pure and applied mathematics. One of her earliest efforts was to forge a partnership with the AMS's Mathematical Reviews to translate new Russian mathematical works into English. This and related undertakings reinforced the United States as an international clearinghouse for postwar mathematics, allowing American institutions to assume a lasting dominance in the discipline.

The ONR led the way for a wide range of government-funded research programs associated with other branches of the military and various civilian offices. These eventually included the National Science Foundation, founded in 1950 after years of debate informed by wartime and early postwar military-sponsored science. ONR and other contracts funded faculty, students, seminars, and publications on a wide scale in the first postwar decades. They supported visiting researchers from abroad and allowed US mathematicians to disseminate their work rapidly and efficiently. These new funding sources allowed the mathematics profession to grow quickly-so quickly, in fact, that US mathematicians could turn from worrying about finding enough sources of support to worrying about finding enough people to make good use of that support.

Over the years, as new mathematical organizations sprang up and the mathematical profession collectively faced new funding and policy issues, the AMS and MAA continued to adapt and reconfigure a series of joint undertakings aimed at the kind of mathematics awareness pursued in the 1940s. ${ }^{1}$ Early postwar joint committees

\footnotetext{
${ }^{1}$ For a blow-by-blow account of the various joint committees, see Everett Pitcher, A History of the Second Fifty Years: American Mathematical Society, 1939-1988 (Providence: American Mathematical Society, 1988), pp. 273-285.
} 


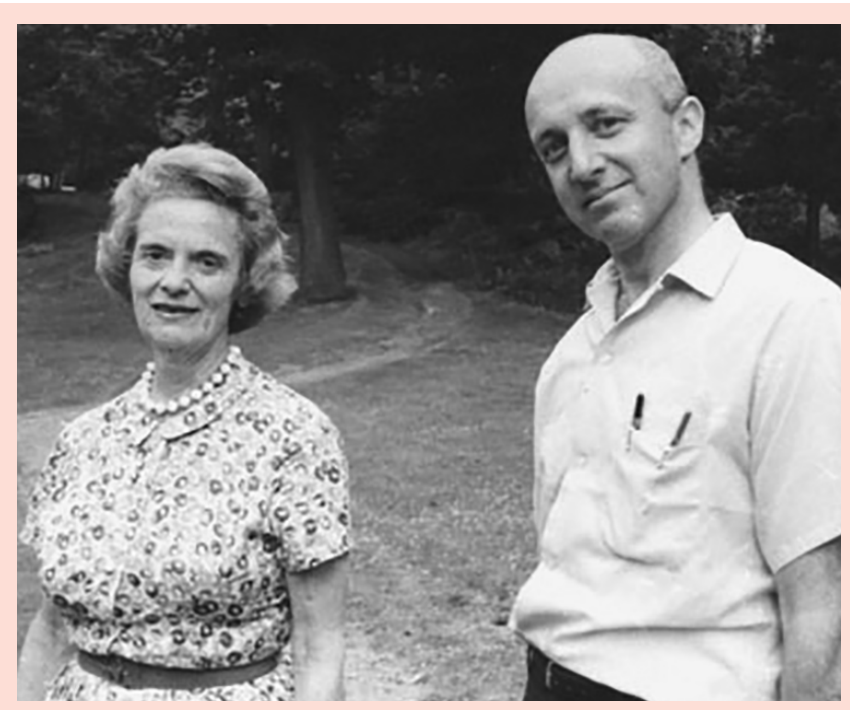

Mina Rees, pictured here around 1966 with Leon Henkin, had an enormous impact in her position as head of the mathematics arm of the Office of Naval Research.

\section{Mina Rees}

In recognition of Rees's contributions to the mathematics profession, the AMS Council adopted a resolution in 1953 asserting:

Under her guidance, basic research in general, and especially in mathematics, received the most intelligent and wholehearted support. No greater wisdom and foresight could have been displayed and the whole postwar development of mathematical research in the United States owes an immeasurable debt to the pioneering work of the Office of Naval Research and to the alert, vigorous and farsighted policy conducted by Miss Rees. (Quoted from the Bulletin of the AMS, March 1954.)

Rees continued after 1953 to serve as an administrator and advisor for a wide range of important boards and institutions, fostering the development of pure and applied mathematics in and beyond the United States.

Further reading: Judy Green, Jeanne LaDuke, Saunders MacLane, and Uta C. Merzbach, "Mina Spiegel Rees (1902-1997)," Notices of the American Mathematical Society 45, (1998) no. 7, 866-873; Amy Shell-Gellasch, In Service to Mathematics: The Life and Work of Mina Rees (Boston: Docent Press, 2011).

laid the groundwork for the International Mathematical Union and advocated for the new NSF and a mathematics division in the National Research Council. The 1970sera Joint Projects Committee in Mathematics eventually grew into the Joint Policy Board for Mathematics, which currently spearheads the annual Mathematics Awareness Month (in 2017 the name became Mathematics and Statistics Awareness Month).

\section{A New Wave}

If more people saw how important math was to their lives, the thinking since the 1980s has been, more people would participate in shaping that mathematics in the future. In practice, it has not always worked out that way. National and even international campaigns for mathematics education have put the power of mathematics on public display, but for many there remain significant barriers to success in the mathematical profession.

The first wave of mathematics awareness took place at a time when American mathematicians were relatively isolated from many areas of policy and the economy and correspondingly lacked obvious places to turn for resources. The second wave responded to a different problem: the need for a public posture that would assure a supply of mathematicians in the future. The Mathematics Awareness Weeks, and later Months, addressed that need by displaying the relevance of mathematics to modern life and to society at large.

We are now starting to see a third wave of mathematics awareness, focused less on what mathematics can do for war-making policy elites or for everyday citizens and more on the mathematicians themselves who create and apply that mathematics and train future generations in their field. Efforts to highlight women and minority pioneers in the discipline and to support underrepresented groups may yet make headway where other approaches have fallen short. The history of mathematics awareness shows that by banding together and working systematically, mathematics organizations can make real changes in how important constituencies view and engage the discipline. The history also shows that mathematics awareness can take many forms, each reflecting the priorities and blind spots of its time.

\section{Photo Credits}

Photo of Mina Rees is from the Marion Walter Photograph Collection, 1952-1980s, undated, Archives of American Mathematics, e_math_01146, Dolph Briscoe Center for American History, University of Texas at Austin.

Michael J. Barany, photo by Yana Stainova. 


\section{COMMUNICATION}

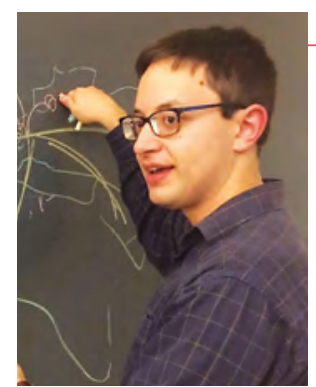

Michael J. Barany

\section{ABOUT THE AUTHOR}

Michael J. Barany is a historian of modern mathematics, currently at the Dartmouth College Society of Fellows. He recently completed his $\mathrm{PhD}$ at Princeton University on the topic of the globalization of the mathematics profession in the mid-twentieth century, with a focus on Laurent Schwartz's theory of distributions. His work on topics ranging from blackboards to "primitive" counting to the Fields Medal has appeared in the Notices of the AMS, New Scientist, The New York Times, and other publications not beginning with $\mathrm{N}$ (including twice in the Best Writing on Mathematics anthology).

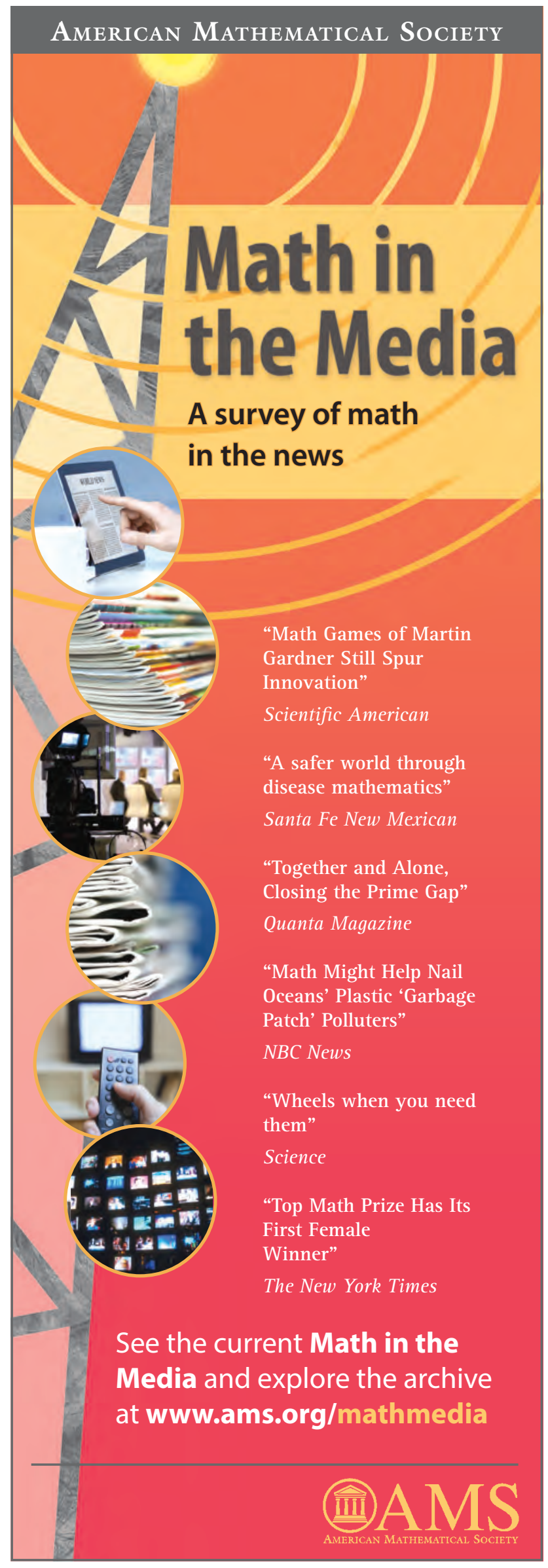




\title{
IMAGINARY-a How-to Guide for Math Exhibitions
}

\author{
Andreas Daniel Matt
}

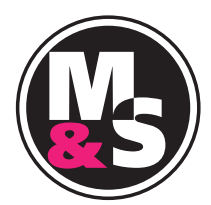

Not so long ago, mathematicians debated the question of why they should communicate about their subject to a broad public. Today, we seem to have collected enough good reasons why and can pass on to the next question: How can we communicate about mathematics to a broad public?

In this article I offer answers to this question in the form of a hands-on guide to planning and organizing interactive mathematics exhibitions. The guide draws on experience from almost ten years of organizing such exhibitions in more than fifty countries, under the umbrella of a project called IMAGINARY. Mathematics and Statistics Awareness Month, celebrated in the US each year in April, provides the perfect occasion to jump in and organize a math exhibition. IMAGINARY can provide a wealth of ideas and resources to get you started.

\begin{abstract}
Math Communication on the Rise
All over the globe, new ways of communicating about mathematics are mushrooming.

New math museums are popping up. Mathematicians produce movies, mobile apps, 3-dimensional prints, and visualizations. They give talks, conduct workshops, visit schools, and write popular books. Math communication conferences are being held on all continents. Mathematical research projects often include outreach components, and math research centers are hiring dedicated outreach mathematicians. More and more professional math communicators are earning a living through this work. There are even independent math communication companies and organizations. A new booming field is arising!
\end{abstract}

Andreas Daniel Matt is the managing director of the nonprofit organization IMAGINARY, based in Berlin, which provides international services for mathematics outreach projects. His e-mail address is andreas . matt@imaginary.org.

For permission to reprint this article, please contact: reprint-permission@ams . org.

DOI: http://dx.doi.org/10.1090/noti1508

\section{IMAGINARY}

IMAGINARY started as a mathematics traveling exhibition for the German Year of Mathematics in 2008. It was a project of the Mathematisches Forschungsinstitut Oberwolfach (MFO), initiated and organized by former MFO director Gert-Martin Greuel and me. The exhibition contained a collection of state-of-the-art mathematical visualizations and interactive programs. One, called SURFER, allows one to experience and explore the relationship between formulas and forms [1].

The exhibition was a big success. With increasing interest from universities, research institutes, and schools, we decided to offer the exhibition through an open license, called an "open science exhibition," which operates in a way similar to open software [2]. Everybody can copy IMAGINARY exhibits and create their own IMAGINARY exhibitions. So far, IMAGINARY exhibitions and events have been staged in collaboration with local partners (mainly mathematicians) in more than one hundred fifty cities, fifty-two countries, and twenty-five languages.

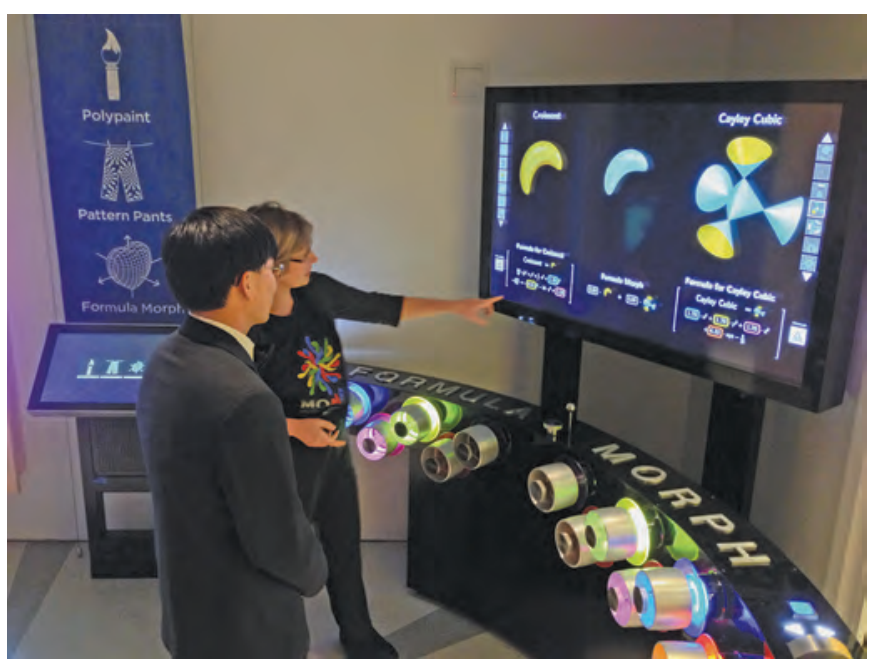

An algebraic geometry exhibit in collaboration with IMAGINARY at the Museum of Mathematics in New York City. 


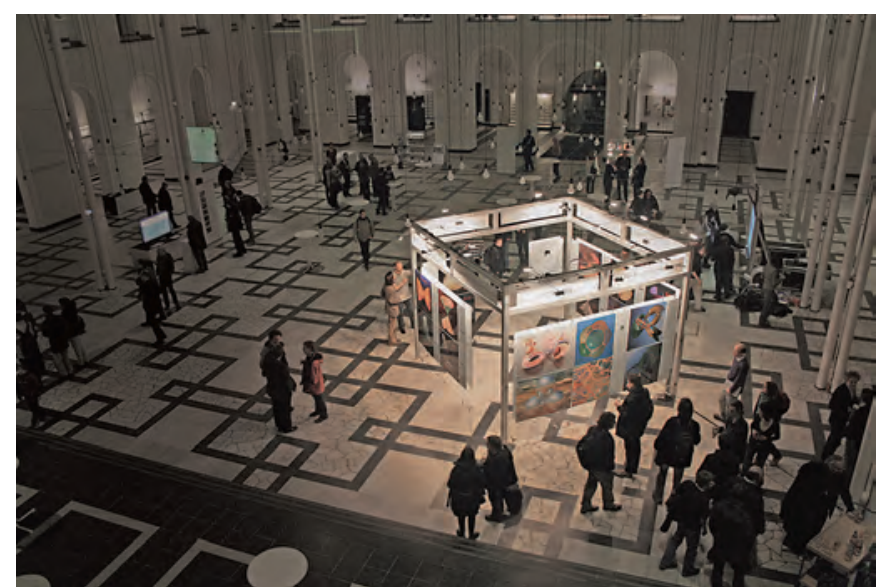

IMAGINARY exhibition in Hannover, Germany, 2009.

There are more than ten permanent IMAGINARY museum installations, for example, at the Deutsches Museum in Munich, one of the world's oldest and largest science and technology museums, and the Museum of Mathematics in New York City.

More than 2.5 million people have visited an IMAGINARY exhibition, and many more have downloaded modules and background material from the website www.imaginary.org. This platform hosts information about mathematics outreach events and includes computer programs, picture galleries, hands-on exhibits, films, and texts, as well as fully developed exhibitions. The platform also allows people to add new exhibits, and this has stimulated a large international community and network for knowledge transfer in mathematics.

Examples of collaborations stimulated by IMAGINARY include exhibitions in ten Russian cities on the occasion of the German-Russian Year of Education, Science and Innovation, 2011-2012. Since 2010, institutions in such countries as Spain, Belgium, the Netherlands, Uruguay, France, Taiwan, and South Korea have adopted the IMAGINARY idea, established local teams, and organized nationwide traveling exhibitions. These efforts are continuing in 2017 and 2018 and will be further extended with new exhibits and activities.

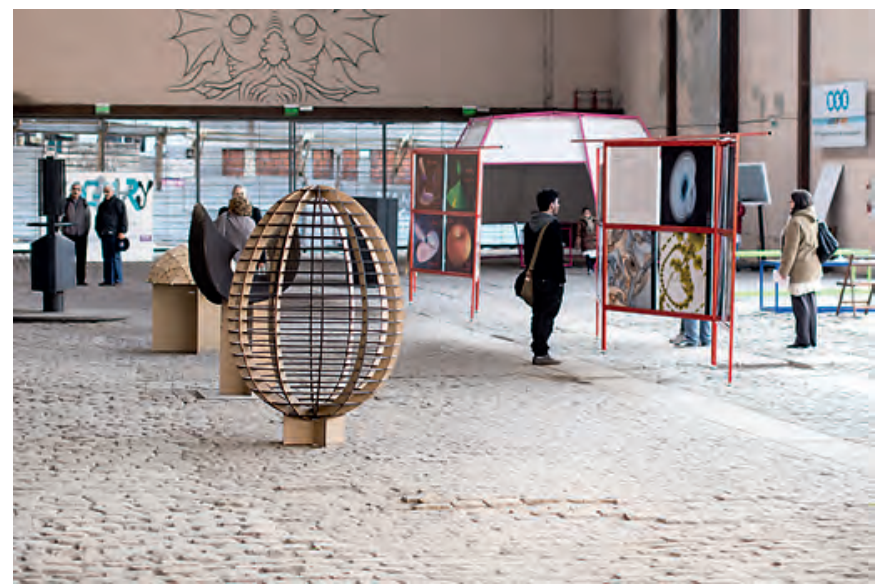

IMAGINARY exhibition in Montevideo, Uruguay, 2015.
A collaboration with the African Institute for Mathematical Sciences (AIMS) was launched in 2014, focusing on mathematics popularization on the African continent. It began with an IMAGINARY event in Dar-Es-Salaam, Tanzania, and continued with workshops, exhibitions, and road shows in Cape Town, South Africa, and in Dakar/M'Bour, Senegal. Further exhibitions are planned in Cape Verde, Mozambique, Democratic Republic of Congo, and Rwanda.

IMAGINARY has grown into a worldwide network of partners and individuals, with many international exhibitions and related events. In this way IMAGINARY has become a hub for transferring mathematical knowledge to society. Three key features of the project stand out: (1) it is close to mathematics research and mathematicians; (2) it is international and multilingual; and (3) it is free, open access, and open source. In addition, IMAGINARY offers physical and interactive content (online and offline) and tries to be as appealing, aesthetic, and advanced in its design as possible. All IMAGINARY activities are highly interactive and participative, involving mathematical and non-mathematical audiences in the creation of exhibitions.

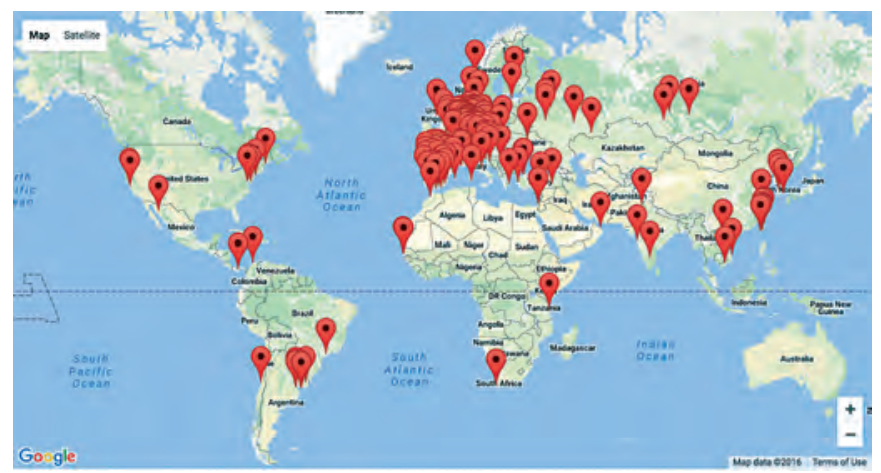

IMAGINARY activities have been organized in more than fifty countries.

Recently, IMAGINARY was organized as an independent nonprofit organization, with support by the Leibniz Association and the Klaus Tschira Foundation. The MFO remains a shareholder of the new organization, which is managed by all former project members.

\section{Stage a Mathematics Exhibition}

To get started planning a mathematics exhibition, you must resolve three main issues: the venue, the budget, and the exhibits. We recommend starting by selecting the venue. The venue often decides the dates of the exhibition and implies the type of audience. It also sets the exhibition space and thus the number of exhibits needed and the budget required. Venues should be attractive and easy to reach and should suit your target audience. They can be colleges or universities, art galleries, schools, public squares, train stations, shopping malls, bank foyers, etc. Often the venues are provided for free in return for co-sponsorship of the exhibition.

The budget for the whole exhibition could vary from US $\$ 2,000$ to US $\$ 200,000$ and depends mainly on whether 


\section{COMMUNICATION}

you use paid personnel or volunteers and on the quantity and quality of the exhibits. Usually the costs are covered partly by the host organization-for example, your college or university-in collaboration with outside partners or sponsors. Typical sponsors are banks, telecommunications firms, high tech companies, and foundations and organizations that promote science and education. Sometimes national or local governments contribute funds.

We classify four forms of exhibits:

- Program: an interactive software exhibit, often used on a touch screen

- Hands-on: a physical exhibit that can be manipulated or a 3-dimensional printed sculpture

- Film: a video that can be shown in an exhibition, for example, in a dedicated cinema room

- Image gallery: a collection of images accompanied by mathematical descriptions.

Ideally, an exhibition lets visitors immerse themselves in a new world. On the IMAGINARY platform you

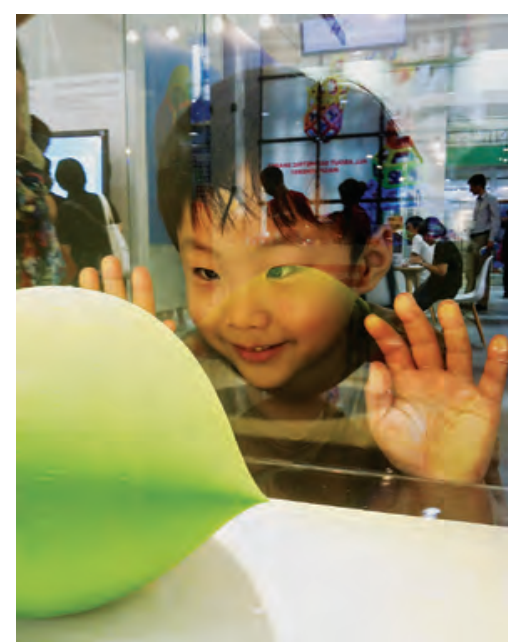

3D-printed algebraic surface at the NIMS-IMAGINARY exhibition during the ICM2014 in Seoul, South Korea.

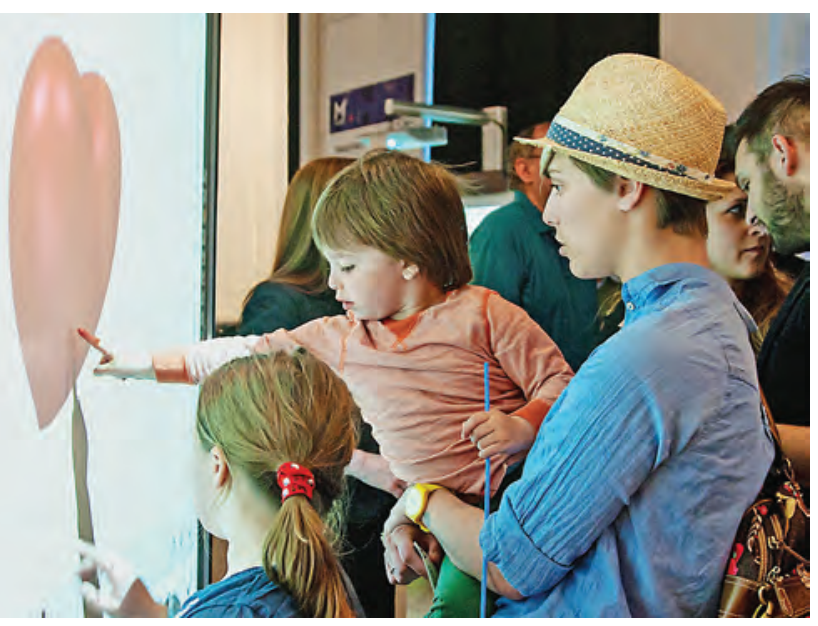

SURFER exhibit on a touch screen at IMAGINARY Belgrade, 2012.

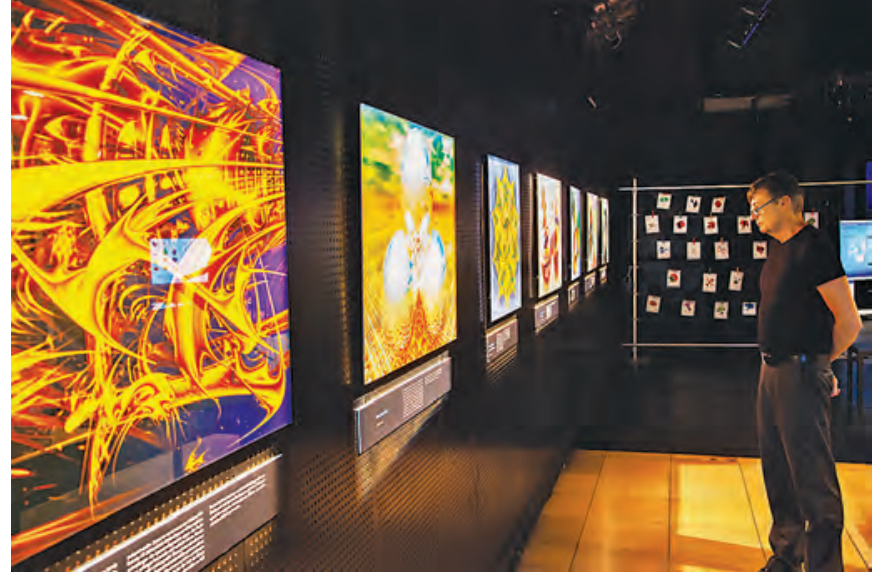

IMAGINARY exhibition at Heidelberg, Germany, with pictures printed in high quality by Luc Benard, Uli Gaenshirt, and Richard Palais, 2014.

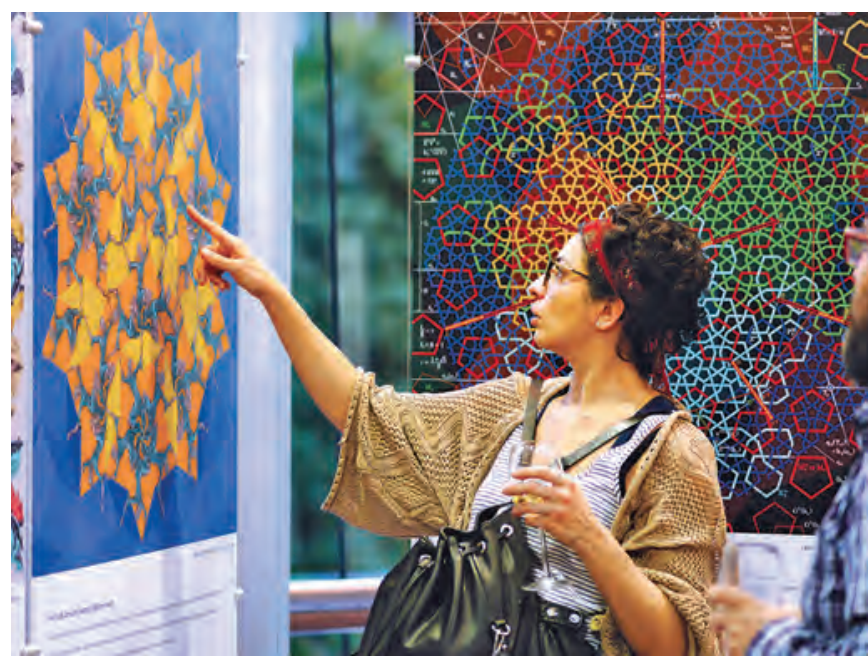

IMAGINARY image gallery on quasiperiodic tilings by Uli Gaenshirt at an exhibition in Istanbul coordinated by IMAGINARY Turkey, 2015.

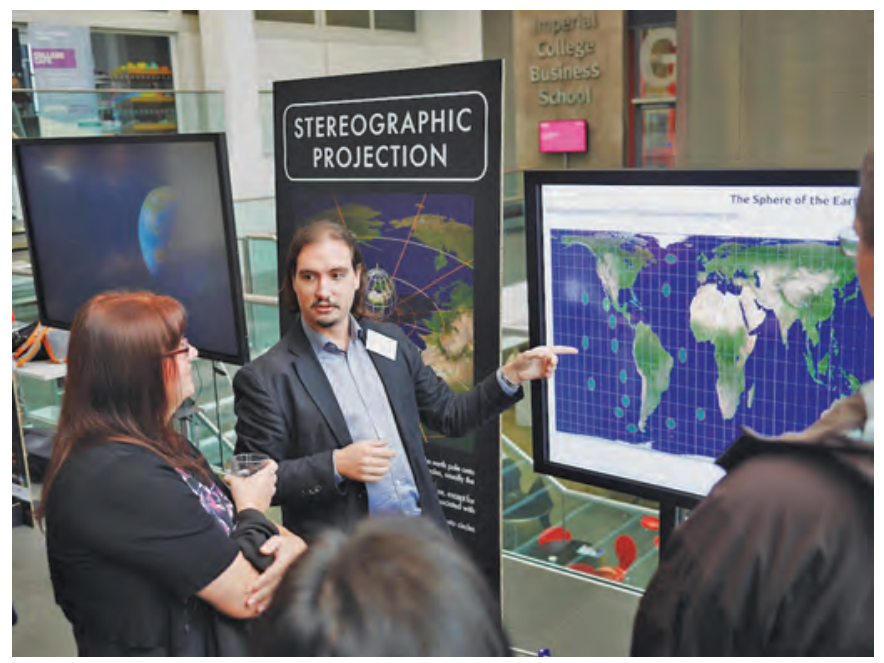

Interactive exhibit "Sphere of the Earth" with explainer at the MPE exhibition, Imperial College London, 2015. 
singularities, as well as explanations. Visitors can print their creations and add them to a user gallery at the exhibition and/or take the images home. Image galleries, video animations, and 3-dimensional printed sculptures of algebraic surfaces make great accompaniments for SURFER. The program can be used to stage online image competitions held parallel to the exhibition and can also be used in schools after the exhibition is over.

A special type of exhibit is the collection of "snapshots of modern mathematics" (see also [3]). These are short papers written by participants of workshops held at the MFO. The idea is to explain as accessibly and understandably as possible suitable topics from their research areas. The snapshots are then edited and shared under an open license. IMAGINARY offers a touch screen station to show these short texts during an exhibition, with an option to print them or e-mail them. By giving a glimpse into ongoing current research, they can give mathematical depth to your exhibition.

Once the venue, budget, and exhibits are set, you step into production and media work. To produce the exhibits, you either have to hire a company or buy the technology yourself. Often colleges and universities already have touch screens and computers that you can borrow. We recommend printing images in high quality and mounting them using a gallery system rather than affixing poster prints to walls. Media work can be carried out through your institution's public relations office or with assistance of IMAGINARY's media channels.

During the exhibition, guided tours can be offered, and you should arrange for tutors to be available on-site to explain the mathematical content. This makes a huge difference! Human explainers, who are often motivated students, inspire the visitors, and together they can explore the mathematics behind the exhibits. IMAGINARY offers special tutorials and training material for tutors.

Once the exhibition is over, the exhibits can be permanently installed in your institution or a local science museum.

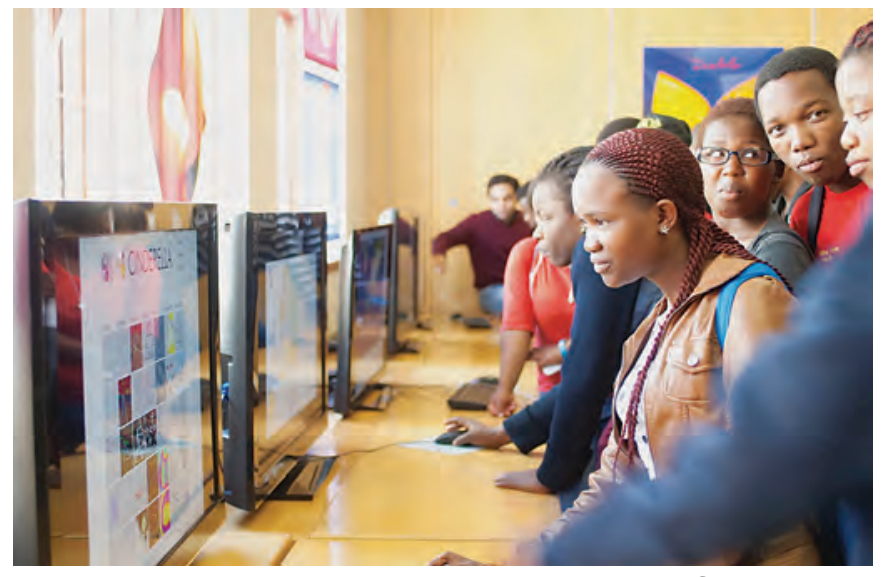

AIMS-IMAGINARY exhibition and workshop for math communicators, Cape Town, 2014.

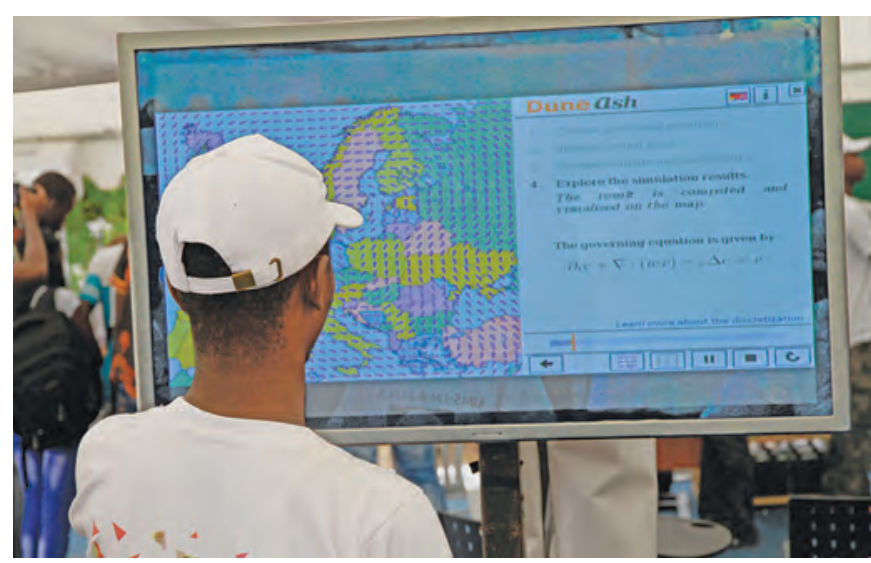

Interactive exhibit Dune Ash at the AIMS-IMAGINARY exhibition in M'bour in Senegal, 2015. It simulates, in real time, the dispersion of volcanic ash from a userchosen volcano location in the presence of a wind field that is drawn by hand.

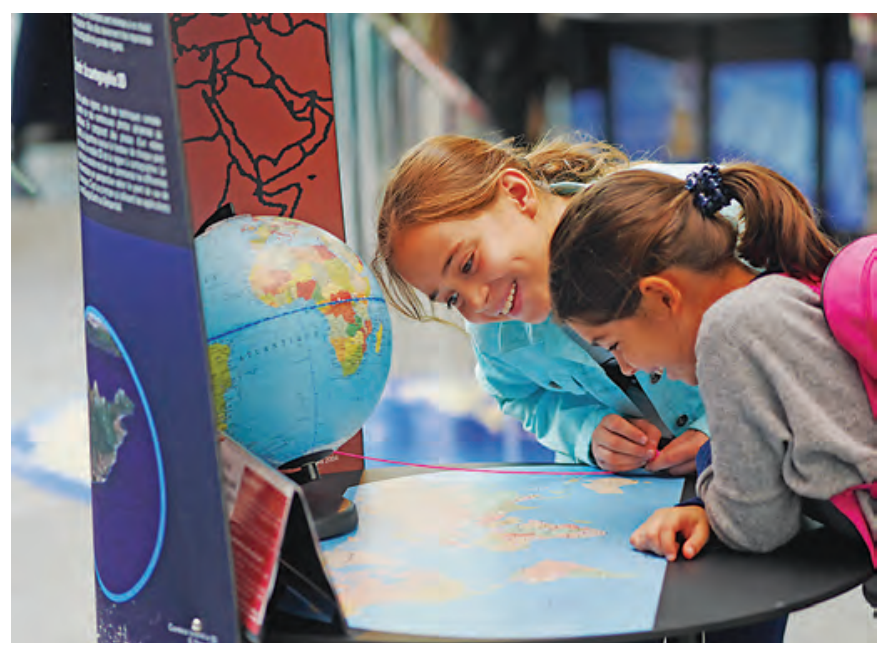

Hands-on exhibit on cartography of the MPE exhibition, Imperial College London, 2015.

\section{Create a Mathematics Exhibit}

An exhibition should always include local content. This means that you or your partner institution should try whenever possible to add your own ideas and your own flair to the exhibition. For example, you can prepare or enhance mathematical visualizations, films, or software simulations for the exhibition.

We have collected many hints about how mathematical knowledge can be transferred to an exhibit. Tools are available to create images in high resolution; movies can be made with digital cameras, via stop motion, or through animation; and 3-dimensional prints can be made at your institution or ordered online in very high quality at affordable prices.

You can then share your exhibit under an open license, which means that your exhibit can then be duplicated at other exhibitions. This way, the collection of available content is constantly changing and evolving, and we all benefit from each other's ideas. In this sense, IMAGINARY 


\section{COMMUNICATION}
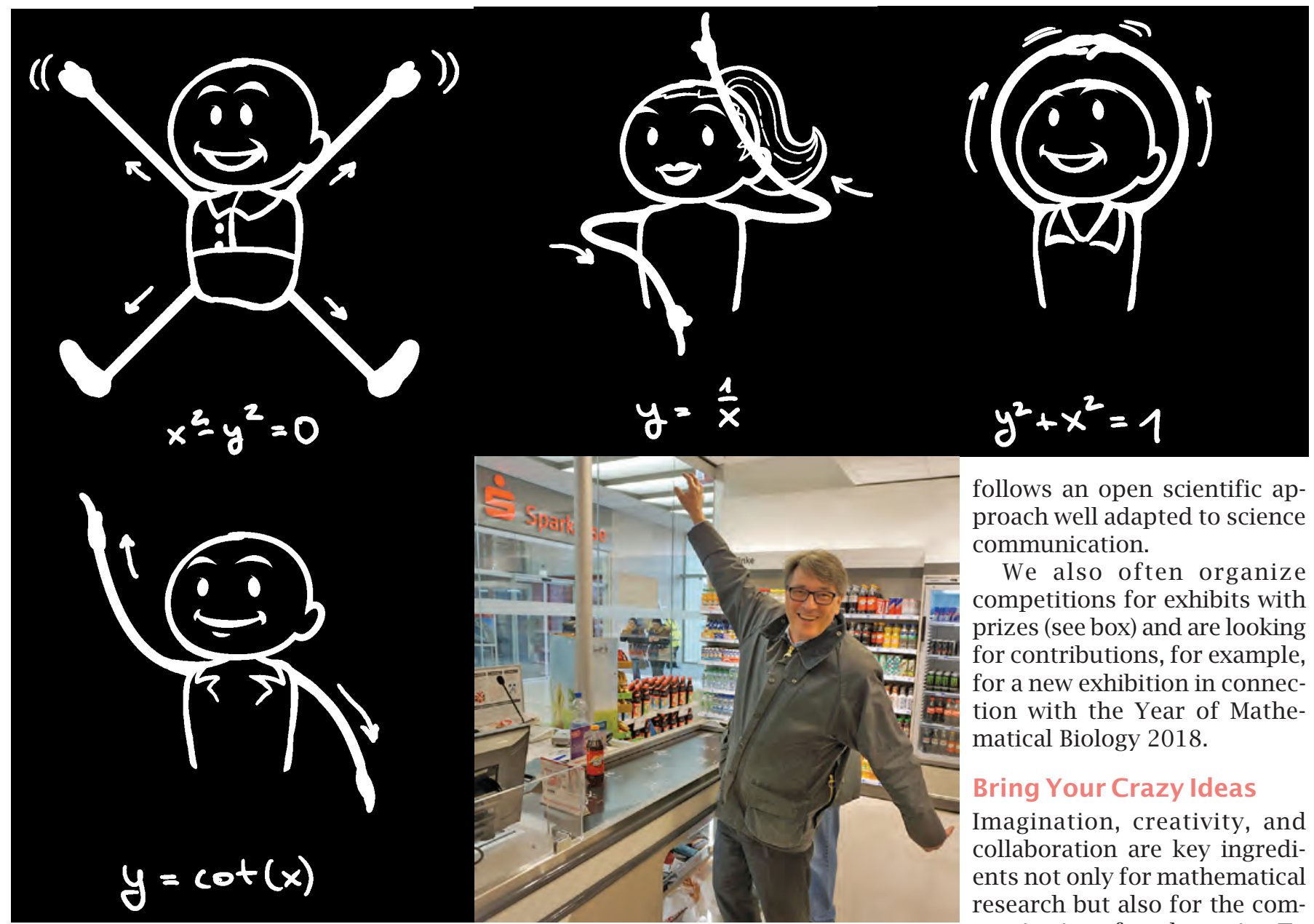

follows an open scientific approach well adapted to science communication.

We also often organize competitions for exhibits with prizes (see box) and are looking for contributions, for example, for a new exhibition in connection with the Year of Mathematical Biology 2018.

\section{Bring Your Crazy Ideas}

Imagination, creativity, and collaboration are key ingredients not only for mathematical research but also for the communication of mathematics. To successfully reach and involve a large audience, we recommend thinking "outside the

\section{Join the Mathematics of Planet Earth Competition!}

Participate in the new competition of exhibition modules for Mathematics of Planet Earth (MPE). You can submit exhibits designed to showcase the ways in which the mathematical sciences can be useful in tackling our world's problems. The best modules will receive prizes and will enrich the successful MPE exhibition. There is a special prize for Africa-related exhibits.

The competition is organized by UNESCO, the International Mathematical Union, the International Commission on Mathematical Instruction, and IMAGINARY.

1st prize: US $\$ 5,000$

2nd prize: US\$2,000

3rd prize: US\$1,000

Special prize for African topic: US\$2,000

Submission Deadline: June 30, 2017

More information at www.imaginary.org/mpe -competition. box." Crazy ideas are welcome!

In IMAGINARY activities, we have seen many creative inventions, which are often initiated in collaboration with artists, designers, musicians, or even chefs-

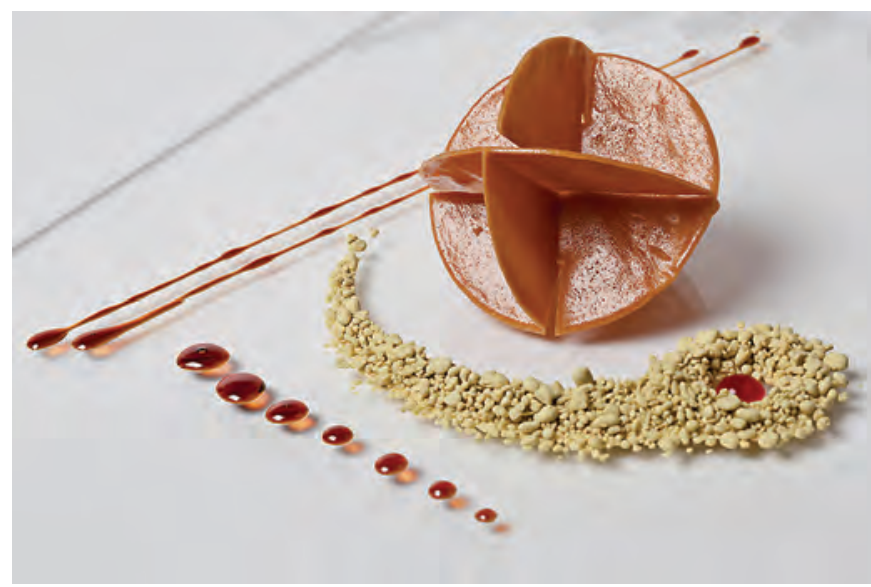

Picture from the exhibition "The Taste of Mathematics," 2012. 
people who visited our exhibitions and got inspired. One example started with the question, How does math taste? Michelin-starred chef José Carlos García teamed up with mathematician Mercedes Siles Molina and photographer Pedro Reyes Dueñas (all three from Malaga) to compare the creative process of cooking with the creative process of doing mathematics. The results are pictures of a mathematical menu and an exhibition plus documentation of the worlds of cooking and doing math. They were inspired by the IMAGINARY exhibition organized in Spain by the Real Sociedad de Matemática Española.

What are the best venues for exhibitions? Surprising venues, like shopping malls, where you would not expect to encounter math, work wonderfully. A prime example is the mathematics-themed shopping mall called Mathematikon Shops that opened in Heidelberg in February 2016. In collaboration with mathematicians from fourteen countries, IMAGINARY equipped the shopping mall-including the conveyor belts, the parking lot, and the restrooms-with mathematical images, puzzles, sculptures, and a huge multitouch interactive station [4].

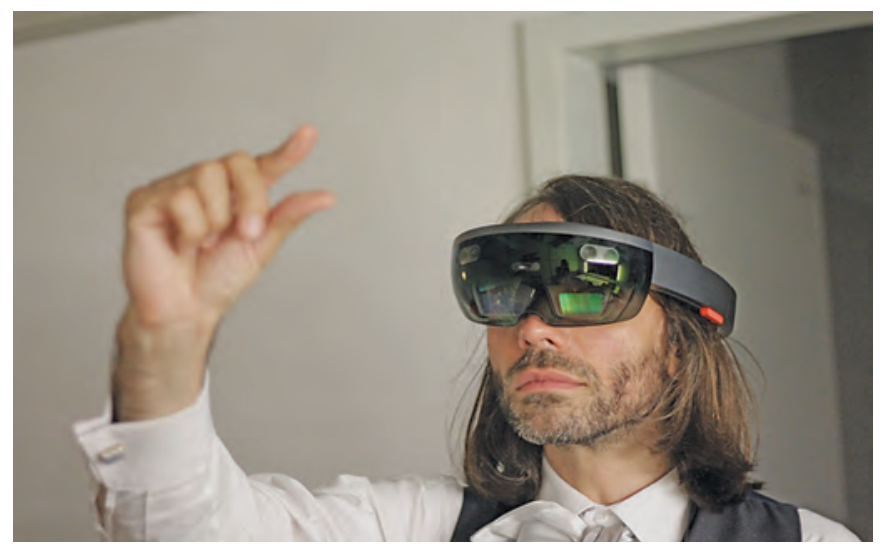

Mathematician Cédric Villani exploring augmented reality for math museums in the holo-math.com project, 2016.

How can new technology be used in mathematics museums? The Holo-Math project initiated by Cédric Villani, director of the Institut Henri Poincaré, in collaboration with IMAGINARY and tech partners, explores how augmented reality can be used to explain and explore mathematical insights. Museum visitors are equipped with HoloLens devices and introduced to mathematically augmented worlds. The first episode of a Holo-Math adventure on Brownian motion is now being finalized.

\section{Stay Connected}

If you want to be informed about current mathematics exhibitions or trends in mathematics communication, please join the Mathematics Communication Network (imaginary.org/network). You can subscribe to its newsletter and participate in joint projects and conferences. To find out about international mathematics outreach projects, including museums, exhibitions, and events, please visit wi kimathcom. imaginary.org, a WikiPage dedicated exclusively to mathematics communication.

If you want to organize an IMAGINARY exhibition and would like support, feel free to contact me. If you organize an exhibition, please announce your event to the online listing of all exhibitions at imaginary.org/events. There you can also find out about all current exhibitions and museum installations, including ones happening in the coming months in Brazil, Germany, the Netherlands-and maybe a place near you!

\section{Credits}

Photos of the IMAGINARY exhibition in Hannover, the world map, the 3D-printed algebraic surface in Seoul, the exhibition in Belgrade, the image gallery in Istanbul, the exhibition and workshop in Cape Town, the interactive exhibit in M'bour, the hands-on exhibit in London, the algebraic geometry exhibit in New York, the math dance in Heidelberg, and the Holo-Math project are courtesy of IMAGINARY.

Photo of the IMAGINARY exhibition in Montevideo courtesy of Matu Tejera.

Photo of the IMAGINARY exhibition in Heidelberg courtesy of Heidelberg Laureate Forum Foundation.

Photo from the exhibition "The Taste of Mathematics" courtesy of Pedro Reyes Dueñas.

Illustrations of dancing functions courtesy of Michael Gralmann. Photo of Andreas Daniel Matt courtesy of Andreas Daniel Matt.

ACKNOWLEDGMENT . For feedback and assistance with the article: Bianca Violet, Nadja Pernat, Gert-Martin Greuel, and Christian Stussak.

\section{References}

[1] G.-M. GREUEL and A. D. MATT (eds.), IMAGINARY-Through the Eyes of Mathematics, Travelling Exhibition Catalogue, published by the Mathematisches Forschungsinstitut Oberwolfach, ISBN: 9-783000-269394, 2008.

[2] A. D. MATT, IMAGINARY and the idea of an open source math exhibition platform, in E. Behrends et al. (eds.), Raising Public Awareness of Mathematics, Springer-Verlag, Berlin-Heidelberg, 2012, DOI 10.1007/978-3-642- 25710-0_26.

[3] C. CEDERbAum and A. CoOPER, Snapshots of modern mathematics from Oberwolfach: Writing about mathematics for a wide audience, Notices of the AMS 63 (2016), no. 8.

[4] B. VIOLET and A. D. MATT, Mathematikon: A mathematical shopping center, Proceedings of Bridges Conference, Jyväskylä, August 2016. 


\section{COMMUNICATION}

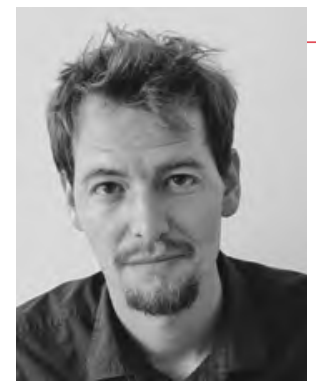

Andreas Daniel Matt

\section{ABOUT THE AUTHOR}

A co-founder of IMAGINARY, Andreas Daniel Matt worked as mathematics communicator at the Mathematisches Forschungsinstitut Oberwolfach from 2007 until 2016. He studied mathematics and computer science and did his PhD in mathematics in machine learning at the University of Innsbruck and the University of Buenos Aires. He curated the MiMa, a museum for minerals and mathematics in Oberwolfach, and is a member of the Raising Public Awareness Committee of the European Mathematical Society. He has received several prizes for his outreach activities, including the Media Prize of the German Mathematical Society in 2013 (together with Gert-Martin Greuel) for the IMAGINARY project.

\section{AMS on Social Networks}

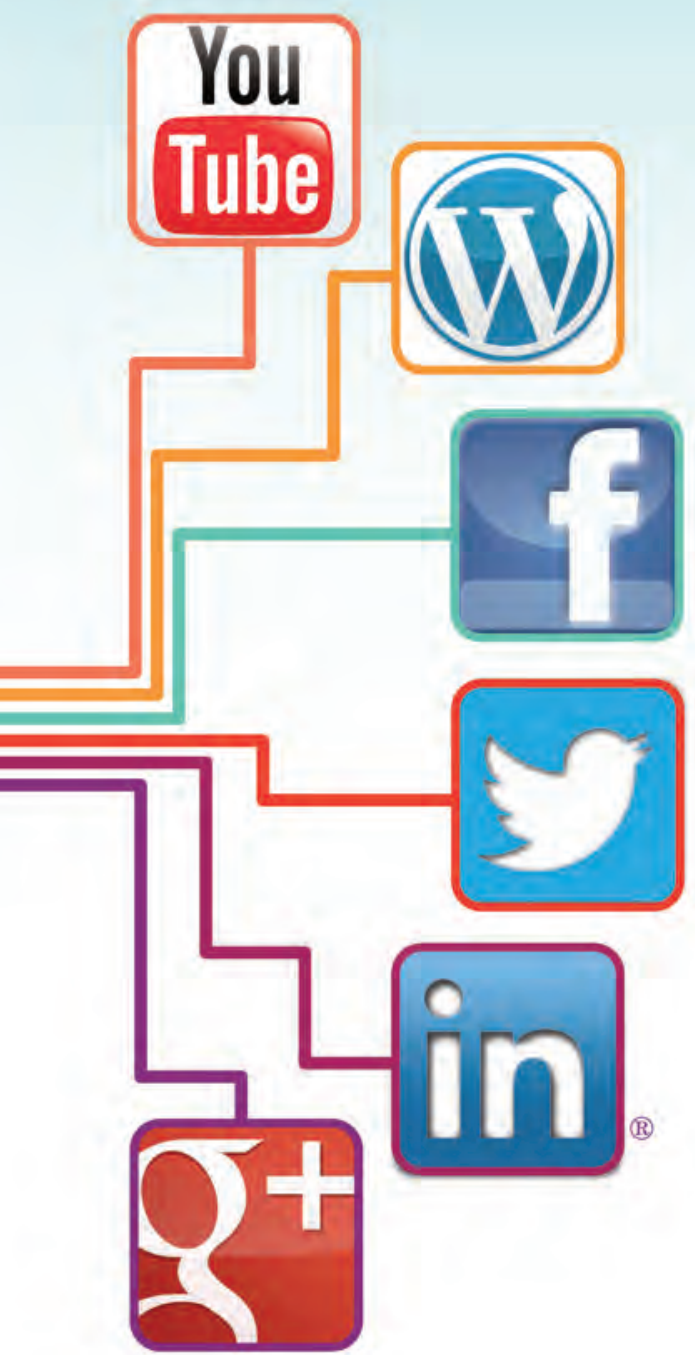

As part of the Society's commitment to the open flow of communication and community engagement, the AMS uses several networking tools to supplement the channels currently in place for members, press and the general public.

We invite you to share AMS website content and set up RSS feeds for website updates and blogs.

www.ams.org/social 


\section{OPINION}

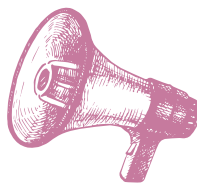

\section{A National Mathematics Festival and a Movement}

David Eisenbud and Kirsten Bohl

\section{Note: The opinions expressed here are not necessarily those of Notices.}

Responses on the Notices webpage are invited.

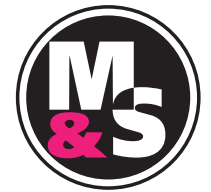

We write this in the last days of 2016, an unsettling and divisive year on many fronts. There's one continuing trend that readers of this column will probably all agree is good: the remarkable increase in public attention paid to mathematics.

By the time you read this, the cherries will be blooming in Washington, DC, where more than thirty thousand children and adults will gather on April 22 at the Washington Convention Center for a day of lectures, puzzles, games, mathletic events, art-making, and performances-that's right, for the second National Math Festival, organized by MSRI in cooperation with the Mathematical Sciences Research Institute in Berkeley in cooperation with the Institute for Advanced Study in Princeton, with MoMath, the National Museum of Mathematics.

We are struck by how different the national backdrop is from the first time in 2015. More and more, our math and science organizations are taking lead roles in encouraging the public to take joy in, understand more deeply, and perhaps feel a deeper and more positive personal connection with mathematics. It would be hard to make a systematic list of all that's happening-that's certainly beyond our capacity and beyond the space for this essay! But here are a few morsels:

David Eisenbud and Kirsten Bohl are director and outreach producer, respectively, at the Mathematical Sciences Research Institute. Their e-mail addresses are de@msri.org and kboh1@ msri.org.

For permission to reprint this article, please contact: reprint-permission@ams . org.

DOI: http://dx.doi.org/10.1090/noti1501
- the weekly "Varsity Math" puzzle column by MoMath in the Wall Street Journal;

- the proliferation of math festivals around the world, including in Mexico City and Rio de Janeiro;

- the creation of Math Outreach International (born in Banff) and the likewise international MATRIX and MOVES conferences;

- the declaration of Global Math Week October 10-17, 2017, and its ambition to make short, engaging math videos entirely visual to obviate the trickiness of language differences;

- the expansion of Bob Moses's Algebra Project and the Flagway Game from their firm successes in inner cities of the United States to small villages in the Irish countryside;

- Math Circles reaching a national spotlight informed about in The Atlantic magazine;

the good things • the nearly two-million-strong Numberphile YouTube channel, which has occasioned we notice. Circles movie; many, many self-reports of turnarounds in feelings about math (and maths);

- the awards accruing to the Navajo Math

- the nascent Mathical Book Prize for young children to teens;

- the international IMAGINARY mathematics exhibitions, described in the previous Notices article, page 368.

It's a heady world these days and one that's different from that of 2015.

As we write this, Francis Su has just launched his MathFeed app, aggregating news, social media, puzzle columns, book reviews, and more about mathematics, 
math education, and related fields. As more of the rising tide of information around us begins to celebrate mathematics in myriad and surprising ways, let's keep one another informed about the good things we notice. At MSRI we will keep developing the More Math! section of the Nationa1MathFestiva1.org website, where we are curating recreational math resources year-round. What will 2017 bring? It's safe to wager we can expect more good news!

When April comes around each year, let's make an even bigger splash with Math Awareness Month. The public understanding of math serves us all, and we are pleased and proud to be shoulder to shoulder with the AMS, AWM, NAM, MAA, SACNAS, and SIAM* to kick up a mathy fuss in fresh and interesting ways. With the Association of Science-Technology Centers, this year MSRI will host Giant SOMA Cube workshops at many dozens of science museums around the country as an extension of the National Math Festival.

If we keep to the trend, the next National Math Festival after this April will be in 2019. We can only guess what the world might be saying and doing and feeling and thinking about mathematics by then, but we do know we want to be in the company of others of goodwill, excitement, and a growth mindset to find out.

*Association for Women in Mathematics, National Association of Mathematicians, Mathematical Association of America, Society for Advancement of Chicanos/Hispanics and Native Americans in Science, Society for Industrial and Applied Mathematics.

\section{Photo Credits}

Photos of David Eisenbud and Kirsten Bohl are courtesy of Cliff Stoll.

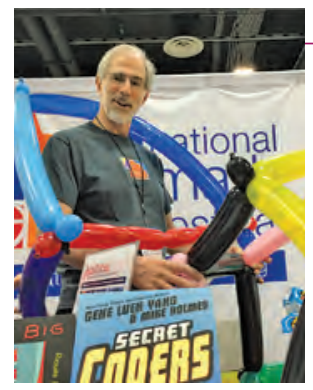

\section{ABOUT THE AUTHORS}

David Eisenbud loves mathematical fun of all kinds-from core research to balloons - and is delighted to see many nonmathematicians reacting in the same way when they get the chance.

\section{David Eisenbud}

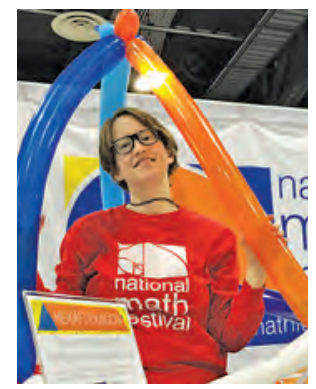

Kirsten Bohl is happiest in her work at MSRI when surrounded by balloons, children, and mathematics - not necessarily in that order.

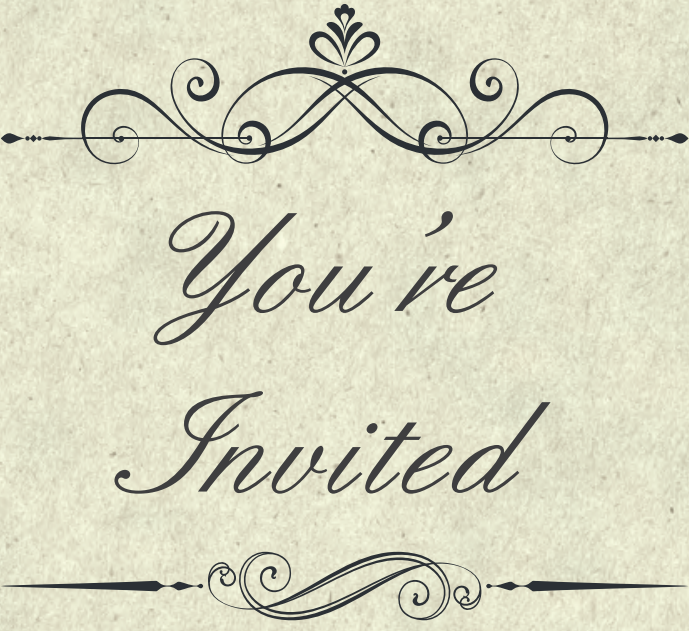

The Editor-in-Chief invites all

readers, from students to retired

folks, to get more involved with

Notices as authors, editors, guest

editors, writers of Letters

to the Editor, and so on.

E-mail your interests, ideas, or nominations of others to

Frank.Morgan@williams.edu.
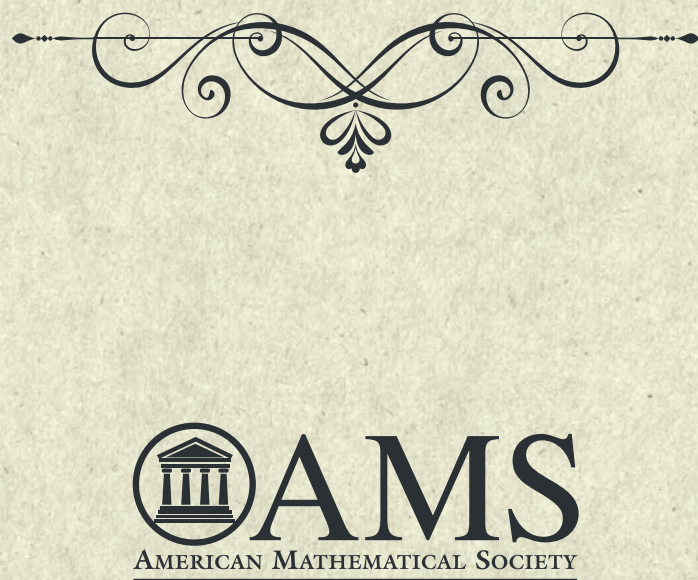

Www.ams.org 


\title{
A Great Time to Be a Statistician
}

\author{
Ronald L. Wasserstein
}

Note: The opinions expressed here are not necessarily those of Notices.

Responses on the Notices webpage are invited.

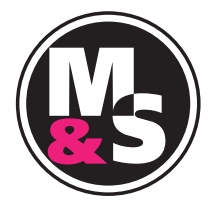

Taking my cue from David Eisenbud and Kirsten Bohl, as I write this I am sitting at my desk just a few miles south of where the cherry blossoms will be harbingers of springtime. However, looking out my window on a chilly January day, barren trees and salty streets say nothing but winter, winter, winter.

As you read this, however, it is Mathematics and Statistics Awareness Month, and it is a great time to make students aware of the opportunities afforded them through study of and careers in math and stats. Our research reveals that when today's high school and college students think about what they would like to do, they want to do work that can make a difference in the world, work that will challenge their intellect and satisfy their curiosity, work that is enjoyable, and (naturally) work that pays well. It is hard to beat mathematics and statistics for jobs that fit these aspirations.

And the word is getting out! Four of the top ten highest rated jobs in the current CareerCast.com survey are directly related to our professions. Similarly, four of the top ten best graduate degrees as ranked by Fortune magazine are in mathematics and statistics. USNews . com ranks "statistician" as number four in its list of twenty-five best jobs. This kind of recognition shows up in other rankings as well, and is being reflected in student degree choices. Since 2010, according to IPEDS data, the number of mathematics bachelors degrees awarded has

Ron Wasserstein is executive director of the American Statistical Association. His e-mail address is ron@amstat.org.

For permission to reprint this article, please contact: reprint-permission@ams .org.

DOI: http://dx.doi.org/10.1090/noti1505 grown by 28 percent, and in statistics by a whopping 170 percent. (That's starting from a smaller base, but still very encouraging.)

The mathematics community, as David and Kirsten have pointed out, is doing wonderful things to promote the importance of mathematics. At the end of this brief column, I say a quick word about one of them. The statistics community is also hard at work to increase student awareness of the value of basic statistical literacy and the potential for careers in statistics. Our biggest investment is an outreach initiative called "This Is Statistics" (www .thisisstatistics.org), and we're very encouraged with the results of this program as it enters its third year. Thousands of students are learning that statistics-the science of learning from data, and of measuring, controlling, and communicating uncertainty-is an excellent career choice.

While 2016 has been labeled the "worst year ever," an assertion that, historical considerations aside, almost any mathematician or statistician would dispute on extreme value theory grounds alone, it was a good year for statistics. ASA Director of Science Policy Steve Pierson has documented this well in his blog "Nine Recognitions for Statistics in 2016." 2

Of these nine, a highlight for me was the announcement of the first recipient of the International Prize in Statistics. The contributions of Sir David $\operatorname{Cox}^{3}$ have impacted

$1 \longdiv { \text { https://www .nytimes.com/2016/12/28/opinion/2016 } }$ -worst-year-ever.htm1?_r=1

$\sqrt[2]{\text { community.amstat.org/blogs/steve-pierson/2016/12/29 }}$ /nine-recognitions-for-statistics-in-2016

3 www . wor 1dofstatistics.org/fi1es/2016/10/W0S news1etter_10202016_SPECIAL.pdf 
the well-being of most of us, so it was fitting that Dr. Cox is the winner of the statistics equivalent of top prizes in other fields, such as the Abel Prize in mathematics. These prizes serve to remind the public that the work of statisticians and mathematicians may be very abstract but it often impacts how we live.

In this "post-truth world," mathematicians and statisticians everywhere ought to engage the public to increase understanding in and trust of our fields. It is encouraging to see how much great work in the area of public engagement is already being done by our communities.

One sterling example of public engagement is the National Museum of Mathematics, which my ASA colleague Donna LaLonde and I visited last year. We spent part of our time viewing the exhibits, and part of our time just watching visitors engage with them. In the building that day were a large group of middle school-aged children. In our observation it wasn't obvious that a single child learned anything specific about mathematics, but it was clear that they all came away with the idea that mathematics is pretty cool. That's an idea very much worth planting, and we are excited to work with you to grow awareness and enthusiasm for mathematics and statistics.

\section{Photo Credit}

Photo of Ronald L. Wasserstein and family is courtesy of Ronald L. Wasserstein.

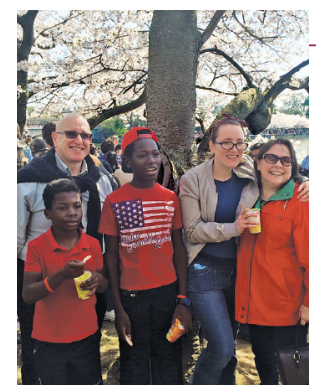

\section{ABOUT THE AUTHOR}

Ron Wasserstein and family (Peterson, Abner, Rose, and Sherry) enjoying the cherry blossoms in Washington, DC.
Ronald L. Wasserstein

\section{Let Your Voice Be Heard!}

\section{Do you enjoy what you're reading in the Notices?}

\section{Would you like to see an article on a certain topic? Person? Situation?}

Then we want to hear from you. Use our Notices Online Commentary Feature to post your general comments and suggestions:

\section{www.ams.org/notices}

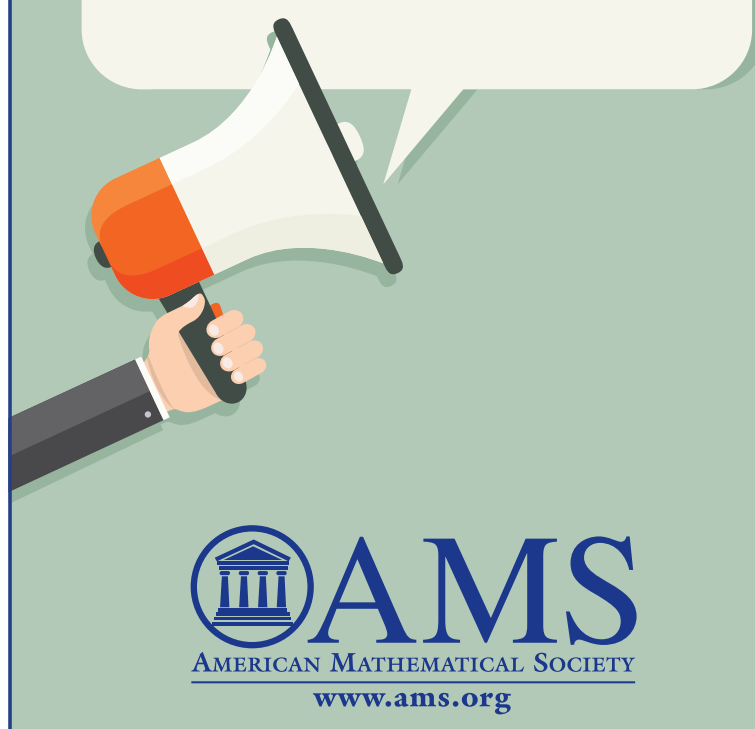

